\title{
The Impact of Inflation Anchor Strength and Monetary Policy Transparency on Inflation During the Period of Emerging Market Volatility in Summer 2018
}

\author{
Tatiana Evdokimova, Nordea Bank \\ tatiana.evdokimova@nordea.ru \\ Grigory Zhirnov, Nordea Bank \\ grigory.zhirnov@nordea.ru \\ Inge Klaver, Nordea Bank \\ inge.klaver@nordea.com
}

This paper examines the link between foreign exchange dynamics and inflation in developing countries with respect to the degree of inflation expectation anchoring they employed in 2011-2019. Particular attention is paid to analysis of the inflationary consequences of the considerable weakness of emerging markets' currencies in summer 2018. Analysis of 2011-2019 confirms that inflation accelerates less in reaction to FX weakness in countries with more anchored inflation expectations. However, similar statistically significant differences were not found during the shock of 2018. One way of anchoring inflation expectations is to make monetary policy more transparent. We have updated the central bank transparency index introduced in Dincer and Eichengreen (2007) and confirm that central bank transparency in emerging markets has considerably improved in recent years. Inflation expectations in these countries have been approaching inflation targets as central banks' policies become more transparent. We also provide some suggestions for improving the quality of monetary policy communication by the Bank of Russia in order to increase its transparency and consequently contribute to a further decrease in inflation expectations.

Keywords: inflation

expectations, monetary policy

transparency, inflation

targeting, emerging markets

JEL Codes: D84, E31
Citation: Evdokimova, T., Zhirnov, G. and Klaver, I. (2019). The Impact of Inflation Anchor Strength and Monetary Policy Transparency on Inflation During the Period of Emerging Markets Volatility in Summer 2018. Russian Journal of Money and Finance, pp. 71-88.

doi: $10.31477 /$ rjmf.201903.71 


\section{Introduction}

Over recent decades many central banks in developing countries have switched to inflation targeting. According to the International Monetary Fund (IMF, 2019), as of 2018 this regime had been implemented in 41 countries, including 30 developing counties. As inflation expectations are a key factor in ensuring price stability, central bankers have put particular effort into anchoring them around the inflation target. As the experience of many developing countries shows, anchoring can be a lengthy and tedious process. It requires constant effort from the central bank to keep inflation close to the declared target and to maintain clear communication with the market. Analysis of periods of financial stress allows the benefits of anchored inflation expectations in times of elevated market volatility to be assessed, and enables us to establish whether central banks' efforts are in fact worthwhile. In this paper we perform this analysis for the period of increased volatility in emerging markets during the summer of 2018. Our hypothesis is that countries with more anchored inflation expectations are more resilient to external shocks.

This article consists of six sections. Section 2 contains a review of research on the topic of inflation expectations. In Section 3 we analyse the impact of FX weakening on inflation in countries with more and less anchored inflation expectations in 2011-2019. Particular attention is paid to analysis of capital outflow from emerging markets in 2018 and to the inflationary consequences of this outflow with respect to the degree to which inflation expectations were anchored. This episode of financial market volatility is very recent and therefore has not yet received a full analysis, lending this paper both novelty and relevance. In this analysis we apply the approach suggested in an IMF publication (2018) concerning the 'taper tantrum' and its consequences for emerging markets back in 2013. In Section 4 we compare the dynamics of inflation expectations in Russia and other emerging countries to obtain anecdotal evidence for the average time needed to anchor inflation expectations. Clear communication by the central bank with the market is a key tool for anchoring inflation expectations. For this reason, Section 5 is dedicated to measuring the evolution of central bank transparency since 2014, when Dincer and Eichengreen (2014) published their estimates of central banks' transparency. We update their research following their methodology to determine what progress has been made. This element of our analysis sheds light on the progress achieved by the Bank of Russia (CBR) in terms of its communication in 2015-2018, the period immediately after the transition to inflation targeting. Even though this progress was slightly faster than the average for emerging markets, there is still plenty of room for the Bank of Russia to further improve its communication. The present paper contains some suggestions to this effect. Section 6 concludes. 


\section{Literature review}

Inflation expectations are extensively analysed in a wide range of research papers. Here we give a short review of the papers that are most relevant to this research, discussing the process by which inflation expectations are formed, ways of managing these expectations, and best practices for central bank communication.

The fundamental theory of the nature of inflation expectations was first formulated by Milton Freedman (1951, pp. 119-124), who developed the concept of adaptive inflation expectations. According to this theory economic agents form their inflation expectations based on current or previous inflation alone, and do not try to predict the future. According to this theory, systematic error will always be present in inflation expectations, and a great deal of time is needed to change these expectations. An opposing theory of rational inflation expectations was formulated by Robert Lucas (Lucas and Sargent, 1981). In this theory inflation expectations are formed on the basis of all available information about the future, no longer focusing only on previous experience. As a result, there is no systemic error in rational expectations, which adjust immediately to new information.

A separate strand of research concerns the process by which inflation expectations are formed. Loleyt and Gurov (2011) put forward a theoretical model whereby inflation expectations are a function of the inflation-related information perceivable by economic agents, and also of agents' trust in the ability of the central bank to keep actual inflation on target. Agents' ability to perceive information directly depends on their education, while their degree of trust is determined by the previous track record of inflation targeting. The more agents trust central bank policy, the easier it is to bring their inflation expectations in line with the official inflation forecast. The lower the ability of the agents to perceive relevant economic information, the more adaptive (based on their previous experience of inflation) their inflation expectations become.

In a theoretical paper, Brazier et al. (2008) also suggest that economic agents may form their inflation expectations based on either past inflation or the inflation target, depending on which of these two indicators is closer to actual inflation.

A number of papers (Gerberding, 2001; Doepke and Schneider, 2006) prove that, even in developed countries with a long history of inflation targeting, information about past inflation is more important for the formation of inflation expectations than forecasts of future inflation. Eyziak (2010) shows that inflation expectations are only $20 \%$ dependent on information about future inflation, with information about past inflation accounting for the remaining $80 \%$. Inflation expectations thus tend to be relatively backward- 
looking. Carroll (2003) notes that people may not follow economic news in any depth, which makes inflation expectations sticky and slow to react to the changing environment.

Galati et al. (2011) analyse the formation of inflation expectations on the basis of weekly surveys completed by 129 respondents in the Netherlands for a year. Central banks usually use monthly inflation expectation surveys, but the special high-frequency survey used in this paper is useful in tracking the way survey participants react to the economic news provided along with the survey. The paper confirms that short-term inflation expectations (one year ahead) are much more volatile than long-term expectations (10 years ahead). On average more than one third of respondents $(38.5 \%)$ changed their one-week-ahead inflation forecast each week, while the long-term forecast was more stable, with only a quarter of respondents changing their expectations. The expectations of less educated respondents tended to be more volatile.

Most research confirms that increased central bank transparency has positive effects. Loleyt and Gurov (2011) note that detailed communication of central bank decisions enables information asymmetry between the regulator and economic agents to be reduced. It is also important to ensure that different authorities' inflation forecasts are coherent.

The IMF paper (2018) stresses the need to increase the predictability of monetary policy. Poor predictability may signal that economic agents' understanding of central bank policy is insufficient. The paper confirms that there is a direct link between the predictability of central bank policy and the strength of the monetary policy anchor. The authors note that increased transparency and more active and clear communication improve the predictability of central banks' actions.

The media plays an important role in transferring the signals sent by the regulator to economic agents. This is a relatively new topic of research, but an extremely important one, as the media is the key link between a central bank and the population whose inflation expectations are to be anchored. The extent of monetary policy coverage in the media has a direct impact on its efficiency. Berger et al. (2006) analyse the media coverage of the policy actions of the European Central Bank (ECB). The authors show that surprising decisions tend to receive negative media coverage, while decisions accompanied by a press conference given by the head of the ECB usually receive much wider coverage. A decision which is unexpected but extensively explained during a press conference has a good chance of being reported positively by the media. More critical discussion of the ECB's actions becomes more probable in periods when inflation exceeds the target. The paper also highlights the importance of cooperation with media from different countries of the euro zone to ensure the widest possible geographical distribution of information. Applying this 
conclusion to the case of Russia would suggest the importance of cooperation with media from different regions of Russia.

Ehrman and Fratzscher (2005) compare the communication strategies of the Fed, ECB and Bank of England. They confirm the hypothesis that a central bank's communication is most efficient when the various representatives of the regulator share a common view on its policy and when decisions on the key rate are made unanimously.

Plekhanov (2016) analyses the Bank of Russia's communication using the texts of their press releases, demonstrating that the regulator's comments on decisions became much more detailed after the adoption of inflation targeting. The Flesch index of readability score for the Bank of Russia's press releases is similar to that of the major central banks.

Kuznetsova and Merzlyakov (2016) analyse press releases and reports by the Bank of Russia from the point of view of signals from the regulator regarding the future direction of its policy. Their study demonstrates that signals from the Bank of Russia became gradually more precise between 2013 and 2016. At the same time, the Russian regulator prefers signals related to the dynamics of macroeconomic indicators, rather than signals which convey the precise timing of expected monetary policy changes. This gives the Bank of Russia greater flexibility in its decision-making process.

Merzlyakov and Habibullin (2017) assess the impact of the Bank of Russia's press releases on the interbank market rate. The authors confirm that market volatility increases after press releases are published. Interestingly, this effect is observed even in the case of decisions to keep the key rate unchanged.

The above studies confirm that confidence in central banks is extremely important for anchoring inflation expectations near the target. Another relevant factor is efforts to improve the financial literacy of economic agents, which affects their ability to perceive the regulator's signals, assess the economic situation and adjust their inflation expectations accordingly. Improving the quality of central banks' communication, making central banks' actions more predictable, systematically keeping inflation close to the target, and organising programmes aimed at improving financial literacy are all necessary steps for effectively managing inflation expectations.

\section{The impact of FX depreciation on price growth depending on the strength of the inflation expectations anchor}

Anchored inflation expectations are generally seen as an important condition for containing inflationary pressure in the case of external shocks. We evaluate the correlation between exchange rate pass-through and inflation dynamics in countries with more and less anchored inflation expectations, and then dig 
deeper into the case of capital outflow from emerging markets in summer 2018. Our main hypothesis is that exchange rate depreciation is less inflationary in countries with more anchored inflation expectations.

We have followed the approach of the IMF (2018) and divided countries into two groups: 'less anchored' (Russia, Romania, Indonesia, India and Thailand) and 'more anchored' (Chile, Hungary, Mexico, Malaysia and Poland). We intentionally excluded Turkey and Argentina from our analysis, as their extreme inflation and exchange rate dynamics (with FX rate depreciation of $-42 \%$ and $-45 \%$ respectively from March 2018 to September 2018) had country-specific explanations, and they might justifiably be regarded as outliers.

The indicators used by the IMF to measure the degree to which inflation expectations are anchored include the root-mean-square deviation of mean inflation expectations from the target, the dispersion of inflation expectations, the sensitivity of inflation expectations to unexpected inflation changes, and more. IMF researchers calculated these indicators for the period from 2000 to 2017 and ranked countries according to the degree to which they anchored inflation expectations. There are, of course, far more countries with an inflation targeting regime than just the ten included in our analysis, but our sample size was limited by the availability of the inflation expectations data required to divide the countries into two subsamples.

We used monthly data from June 2011 to February 2019 in order to evaluate the impact of local currency depreciation on inflation dynamics in two groups of countries. We applied advanced panel data techniques with country-specific effects. We chose the consumer price index (CPI, yearly change) as a dependent variable. Explanatory variables include a dummy variable reflecting a country's inflation expectations group ( 1 - less anchored countries, 0 - more anchored countries), the first lag of foreign exchange rate change and the first lag of the dependent variable itself (to tackle the endogeneity problem caused by the omitted variables).

Kartaev and Yakimova (2018) show that there are two effects of FX depreciation on prices: short-term and long-term. The main purpose of our analysis is to evaluate FX pass-through to inflation in our two groups of countries and not to estimate the timing of this pass-through effect. For this reason, we focus primarily on shortterm price sensitivity to FX changes and choose the first lag of the exchange rate change as an explanatory factor in our model. We estimate the model in differences in order to account for the non-stationarity of the time series and avoid the spurious regression problem (the stochastic features of the variables are discussed in Appendix 1).

We do not claim that the strength of its inflation expectations anchor is the key determinant of a country's macroeconomic dynamics. Moreover, a number of significant factors exist which influence inflation dynamics and might be used as control variables in our model. Nevertheless, for simplicity 
we use the lagged values of dependent variables, which helps us to avoid the endogeneity problem. IMF researchers (IMF, 2018) used a similar model specification in exploring the consequences of capital outflows from emerging economies in 2013. They chose dummy variables which reflected the degree of inflation expectations anchoring at the time, along with lagged values of dependent variables.

We estimated all our dynamic regressions using the generalized method of moments (GMM) and Arellano-Bond approach (Arellano and Bond, 1991) to obtain consistent estimates of coefficients. All residuals were tested on normality and the absence of second order autocorrelation in differences (test for $\operatorname{AR}(2)$ ). We also used robust estimation of covariance matrices in order to tackle the potential heteroscedasticity problem and so test the hypothesis and construct confidence intervals correctly. We also estimated our models excluding one country from each group at a time, to ensure that the results were not driven by any single country (see Appendix 1).

Model (1), for FX pass-through to CPI, was specified as follows:

$$
\Delta c p i_{t, i}=\alpha \Delta c p i_{t-1, i}+\beta \Delta f x_{t-1, i}+\gamma d 1_{t, i} \Delta f x_{t-1, i}+\omega_{i, t},
$$

where $c p i_{t, i}$ is the CPI change $(\mathrm{y} / \mathrm{y})$ in country $i$ at time $t\left(\Delta c p i_{t, i}=c p i_{t, i}\right.$ - $\left.c p i_{t-1, i}\right), f x_{t, i}$ is the local currency change vs USD $(\mathrm{y} / \mathrm{y})$ at time $t, d 1_{t, i}$ is a dummy variable reflecting the inflation expectations group ( 1 - more anchored group, 0 - less anchored group), and $\omega_{i, t}$ is the random error CPI change (y/y) in country $i$ at time $t$.

Our main hypothesis was that FX depreciation in countries with less anchored inflation expectations led to higher acceleration of inflation in these countries compared to the more anchored group. We therefore expected that the coefficient $\gamma$ would be positive and significant and that the effect of immediate exchange rate pass-through in countries with less anchored inflation expectations would amount to $\beta+\gamma$, while the FX pass-through in countries with more anchored expectations would be defined only by the parameter $\beta$ (as the variable $d 1_{t, i}$ for these countries is equal to 0 ).

The results of estimation of model (1) are presented in Table 1. It is clear that the short-term FX pass-through was more than twice as high in countries with less anchored inflation expectations (Figure 1). The coefficient $\beta$ equals 0.014 , while the $\operatorname{sum} \beta+\gamma$ gives 0.0393 . This means that, if the local currency depreciates by $10 \%$, inflation in the following month will accelerate by 0.14 percentage points (p.p.) in countries with more anchored inflation expectations and by 0.39 p.p. in countries with less anchored expectations. As a result, countries from the less anchored group suffer more from external instability as inflation reacts more intensely to this instability. 
Table 1. FX pass-through to $\mathrm{CPI}$

\begin{tabular}{lll} 
& \multicolumn{2}{l}{ CPI (GMM-Estimation, Arellano and Bond, 1991) } \\
\hline Variables & Coefficient estimates and their significance & Standard error \\
\hline l1.dcpi & $0.3010^{* * *}$ & 0.0309 \\
\hline l1.dfxyy & $0.0140^{*}$ & 0.0067 \\
\hline l1.dfxyy ${ }^{*} \mathrm{~d} 1$ & $0.0253^{* *}$ & 0.0087 \\
\hline Observations & 890 & \\
\hline Hansen's J-statistic & 864.61 & \\
\hline
\end{tabular}

Note: ${ }^{*} \mathrm{p}<0.05,{ }^{* *} \mathrm{p}<0.01,{ }^{* * *} \mathrm{p}<0.001$

Figure 1. Impact of FX depreciation on prices

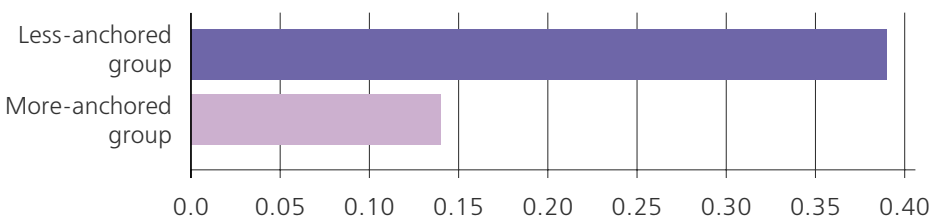

Note: For the more anchored group, the figure shows the regression coefficient in front of $\Delta f x_{t-1, i}$; for the less anchored group, the figure shows the sum of the regression coefficients in front of $\Delta f x_{t-1, i}$ and $d 1_{t, i}^{t-1, i} \Delta f x_{t-1, i}$.

We have also attempted to establish whether these differences in FX passthrough between countries with more and less anchored inflation expectations persisted during the capital outflow from emerging markets in 2018. This shock negatively influenced both the exchange rate and inflation dynamics in these counties. Monetary policy tightening by the Federal Reserve System of the US (the Fed) was the main reason for capital outflow from emerging markets. The Fed started to hike the key rate in 2015 and increased the frequency of its hikes to quarterly in 2018. What's more, the American regulator began quantitative tightening (balance sheet normalization) in 2017Q4. As a result, the USD posted strong results on global markets (DXY gained more than 6\% in 2018Q2), while the cost of borrowing in USD increased (the three-month LIBOR increased from $1.7 \%$ to $2.3 \%$ during $2018 \mathrm{Q} 1$ ). The inflow of capital to emerging markets was reversed. According to the Institute of International Finance, net foreign portfolio investment inflow into emerging markets was negative in 2018Q2 and 2018Q3 (compared to a monthly average of USD 30 billion earlier). Countries with high short-term foreign exchange debt and a high current account deficit (Argentina, Turkey, Colombia and South Africa) were the most affected. In the case of Turkey, the situation was exacerbated by a loss of confidence in the independence of the Central Bank.

In our analysis of the 2018 shock we continued to apply the approach employed by the IMF (2018) and used the same two groups of countries specified above. 
At first glance, inflation in countries with more anchored inflation expectations may appear to have reacted less to the shock than inflation in countries with less anchored expectations (Figure 2). However, if Turkey and Argentina are excluded from the analysis, Figure 2 shows that any difference between the two groups of countries in terms of CPI dynamics was barely visible. Interestingly, the currencies under analysis weakened against the USD to an almost equal degree in both groups (Figure 3).

Figure 2. Inflation dynamics after capital outflow shock

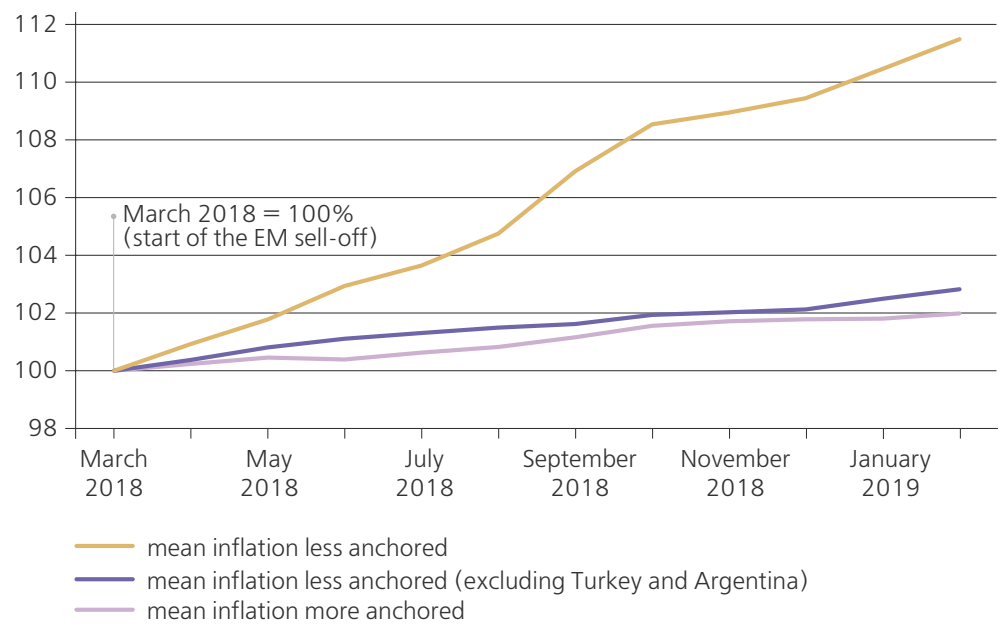

Figure 3. FX dynamics after sell-off shock, \%

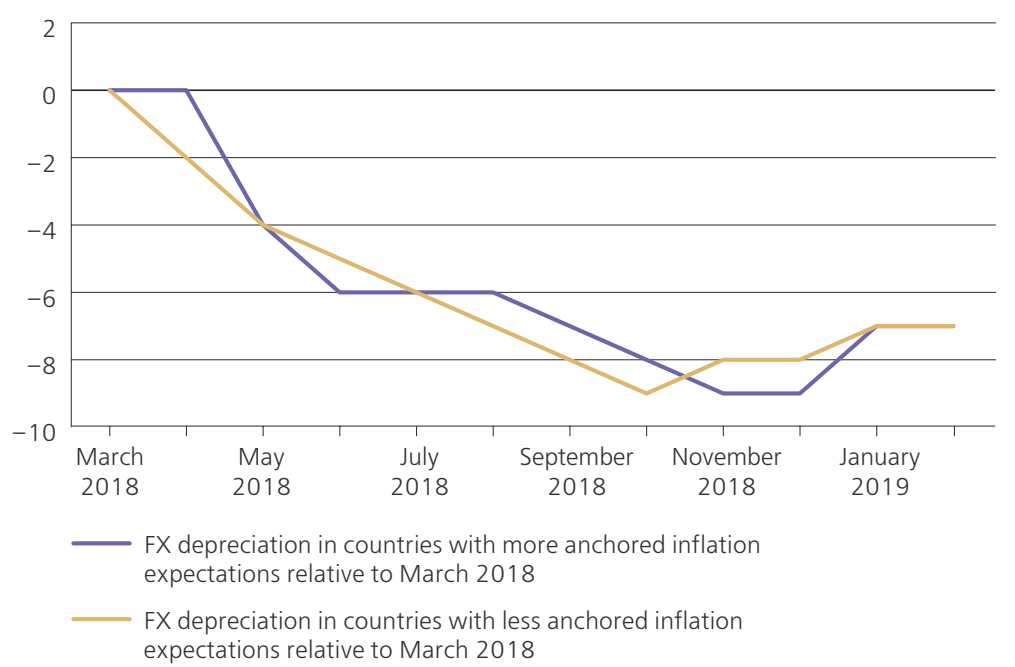


These two observations were confirmed by the econometric model. We applied advanced panel data techniques in order to evaluate the influence of the capital outflow shock on inflation and exchange rate dynamics in our two groups of countries, controlling for country-specific effects. We built the model using monthly data from December 2017 to February 2019. Among the dependent variables were CPI (yearly change) and exchange rate vs USD (yearly change); explanatory variables consisted of a dummy variable for selloff shock (equal to 1 in March-August 2018, otherwise 0), a dummy variable reflecting the inflation expectations group (1 - less anchored countries, 0 - more anchored countries) and lagged values of the dependent variables themselves as in model (1).

Model (2), for the FX rate, was specified as follows:

$$
f x_{t, i}=\alpha f x_{t-1, i}+\beta d 1_{t, i} d 2_{t}+\gamma d 2_{t}+\omega_{i, t},
$$

where $f x_{t, i}$ is the local currency change vs USD (y/y) at time $t, l 1 . f x=f x_{t-1, i}$, $d 1_{t, i}$ is a dummy variable reflecting the inflation expectations group ( 1 - more anchored group, 0 - less anchored group), $d 2_{t}$ is a dummy variable reflecting selloff shock, and $\omega_{i, t}$ is a random error.

Model (3), for CPI, was specified as follows:

$$
c p i_{t, i}=\alpha c p i_{t-1, i}+\beta d 1_{t, i} d 2_{t}+\gamma d 2_{t}+\omega_{i, t},
$$

where $c p i_{t, i}$ is the CPI change $(\mathrm{y} / \mathrm{y})$ in country $i$ at time $t, l 1 . c p i_{t, i}=c p i_{t-1, i}$ $d 1_{t, i}$ is a dummy variable reflecting the inflation expectations group, $d 2_{t}$ is a dummy variable reflecting sell-off shock, and $\omega_{i, t}$ is a random error.

If the exchange rate and inflation dynamics were truly dependent on the capital outflow shock in 2018 , the variable $d 2_{t}$ should be significant in both models. For us to state that inflation accelerated faster in countries with less anchored inflation expectations, the coefficient $\beta$ would need to be positive and significant. Thus, the increased inflationary response to capital outflow shock in countries with less anchored expectations is reflected by the sum of coefficients $\beta+\gamma$, while in countries with more anchored inflation expectations this effect amounts to $\gamma$ alone.

Our models confirm that the effect of capital outflow in 2018 (dummy variable $d 2$ ) was statistically significant for both exchange rate (Table 2) and inflation dynamics (Table 3). Nevertheless, both regressions show that the degree of FX depreciation and CPI acceleration was almost identical in the two groups of countries: the coefficient $\beta$ in both models was insignificant at any reasonable level of significance (Tables 2 and 3 ). 
Table 2. FX reaction to shock

\begin{tabular}{lll} 
& \multicolumn{2}{l}{ FX (GMM-Estimation, Arellano and Bond, 1991) } \\
\hline Variables & Coefficient estimates and their significance & Standard error \\
\hline $\mathrm{d} 2$ & $3.3028^{* * *}$ & 0.8564 \\
\hline $\mathrm{d} 1^{\star} \mathrm{d} 2$ & -1.1033 & 1.3788 \\
\hline $\mathrm{ll} . \mathrm{fx}$ & $0.9279^{* * *}$ & 0.1128 \\
\hline Observations & 130 & \\
\hline Hansen's J-statistic & 38.88 & \\
\hline
\end{tabular}

Note: ${ }^{\star} \mathrm{p}<0.05,{ }^{* *} \mathrm{p}<0.01,{ }^{* *} \mathrm{p}<0.001$.

Table 3. CPI reaction to shock

CPI (GMM-Estimation, Arellano and Bond, 1991)

\begin{tabular}{lll}
\hline Variables & Coefficient estimates and their significance & Standard error \\
\hline $\mathrm{d} 2$ & $0.2380^{*}$ & 0.1109 \\
\hline $\mathrm{d} 1^{*} \mathrm{~d} 2$ & -0.0512 & 0.1857 \\
\hline l1.cpi & $0.7683^{* * *}$ & 0.0994 \\
\hline Observations & 130 & \\
\hline Hansen's J-statistic & 16.44 & \\
\hline
\end{tabular}

Note: ${ }^{*} \mathrm{p}<0.05,{ }^{* *} \mathrm{p}<0.01,{ }^{* * *} \mathrm{p}<0.001$.

The hypothesis that inflation increased faster in countries with less anchored inflation expectations during the shock in 2018 is therefore rejected. The exchange rate weakened by the same amount on average in both groups of countries during the period of the shock, and this weakening did not lead to a statistically significant difference in inflation dynamics in these groups of countries. This suggests that exchange rate pass-through to prices in countries with different degrees of anchoring of inflation expectations did not differ significantly in the period of capital outflow in 2018.

We note that the results of our analysis (capital outflow from emerging markets in 2018) and the IMF analysis of a similar episode in 2013 differ in spite of the fact that the magnitude of these shocks was comparable in terms of their impact on the exchange rates of developing countries. During the shock of 2013, as the IMF shows, inflation in countries with less anchored inflation expectations accelerated significantly faster than in the group of countries with more anchored expectations, which was associated with a higher exchange rate pass-through to prices. The results of our research have not revealed similar differences in the dynamics of inflation, although they have confirmed the importance of the impact of the capital outflow shock in 2018 both for the dynamics of inflation and for the exchange rate. This discrepancy between our research and the IMF's study can be explained by the fact that in 2018 central banks in developing countries (in particular, the central banks of Mexico, Romania, Indonesia and Chile) tightened monetary policy more quickly than at the time of the shock of 2013. Indeed, the central banks of these countries reacted more proactively to the shock in 2018, taking into account their experience 
of previous large-scale capital outflow, which probably helped to mitigate its negative consequences for price stability. Nevertheless, on a broader time horizon, as we have shown in model (1), the short-term effect of exchange rate depreciation on inflation is halved in countries with more anchored inflation expectations, which confirms that managing inflation expectations has positive effects.

\section{Inflation expectations in Russia}

The CBR managed to bring inflation in line with the target quite fast after adopting inflation targeting, as early as the first half of 2017, i.e. less than 2.5 years after switching to a new monetary policy regime. Inflation was therefore brought in line with the target much faster than average for an emerging market country targeting inflation. Our calculations using IMF data show that it takes developing countries an average of 4.5 years to bring inflation in line with the target after switching to inflation targeting.

Inflation expectations were also sustainably declining in Russia until the middle of 2018, but more than four years after the adoption of inflation targeting, they are still unanchored, exceeding the CBR target by around 5 p.p. In comparison, 11 countries for which sufficiently long time series are available (Chile, Mexico, Peru, Turkey, South Africa, Guatemala, Serbia, Romania, the Czech Republic, Colombia and Hungary) managed to reduce the discrepancy between inflation expectations and the target to just 1.7 p.p. on average over the same timeframe. Thus, while inflation in Russia was brought in line with the target ahead of schedule, the task of combatting elevated inflation expectations is proving more challenging. The experience of the same 11 countries shows that it takes seven years on average to bring inflation expectations in line with the target. Two distinct groups of countries can be distinguished: in the countries of the first group (for example Chile, Mexico and Peru) the whole process took no longer than three years, while in the other countries it took around a decade. Russia does not seem to belong to the first group.

The gap between inflation expectations and the inflation target is a commonly used as an indicator of confidence in a central bank's policy. So far the CBR has already managed to win the confidence of the expert community and financial market participants, but it still has some way to go to win over companies and the public.

\section{Inflation expectations and monetary policy transparency}

Our analysis for 2011-2019 confirms that more firmly-anchored inflation expectations help to reduce the magnitude of FX pass-through to prices. As is extensively documented in academic research, better anchoring of inflation expectations requires continuous improvements in the fiscal sustainability and credibility of central banks through better communication and transparency 
(Montes and Acar, 2018). The benefits of transparency are increasingly widely recognized, and especially since the widespread adoption of inflation targeting regimes in many countries and the spread of democratization and financial liberalization, central banks are putting more effort into improving their transparency (Mishkin, 2000; Dincer and Eichengreen, 2007).

It is increasingly important for central banks to be credible and accountable to the public. To that end, there has been a general trend towards more communication in advanced and emerging market countries alike. Transparency contributes to the transmission of monetary policy in several ways (Freedman and Laxton, 2009). Firstly, it improves public understanding of the goals and means of the central bank, lending it credibility. Secondly, transparency contributes to the effectiveness of policy insofar as it helps to set inflation expectations by providing agents with the same set of information that the central bank possesses to form their expectations and even disclosing likely future policy actions.

A widely used index of central bank transparency that captures many aspects of policymaking is that of Dincer and Eichengreen (2007). Their index was in turn based on the work of Eijffinger and Geraats (2006). The index aggregates results for five dimensions of transparency, capturing the political, economic, procedural, policy and operational aspects of monetary policy transparency with three questions per dimension, adding up to a total maximum score of 15 .

The first dimension, political transparency, refers to the central bank's openness about policy objectives, such as its mandate and relations with the government. Economic transparency means openness about data, models and forecasts. Procedural transparency refers to the way monetary policy decisions are taken, for instance whether the central bank publishes the minutes of their meetings. Policy transparency concerns the provision of information on the implications of policy, explanations for decisions and guidance about future actions. Lastly, operational transparency is openness about the implementation of these decisions and discussions of the transmission of monetary policy.

Dincer and Eichengreen $(2010,2014)$ originally published their index for a large number of countries for the years 1998-2006, subsequently updating their full sample in 2014. As we are interested in how central bank transparency in emerging markets has progressed over the last few years, we carry out another update of Dincer and Eichengreen's transparency index for 2019, but for a smaller sample of developing countries. The score reflects the situation that prevailed at the beginning of the year. We draw our data from information on central banks' websites and in their inflation reports, statutes and other published documents. We admit that the results are likely very subjective. Nevertheless, they enable us to obtain an idea of the general trend in the degree of transparency in developing countries.

In their original analysis, Dincer and Eichengreen found that central banks in advanced countries are more transparent than central banks in emerging markets. 
Their results also show that there has been a steady increase in transparency over the period 1998-2014 for advanced countries and emerging markets alike.

The average transparency score in our sample rose from 7.7 out of 15 in 2014 to 10.1 in 2019 , with nearly all countries showing some improvement, but there is substantial heterogeneity. The scores for 2014 and 2019 are plotted together in Figure 4. Peru is the only country on the diagonal, indicating no change in the transparency score. Romania, Argentina, Chile, Mexico and Russia made the biggest improvements in their transparency, and Hungary was the most transparent country in our sample in both 2014 and 2019. China was at the same level as Russia and India until 2010 but has fallen behind since then and is now at the bottom of our sample. Russia's score has increased from 7.5 to 11 points, which is a faster than average increase for our sample. A detailed table with country scores for all components may be found in Appendix 2.

Figure 4. Central bank transparency index in 2014 and 2019

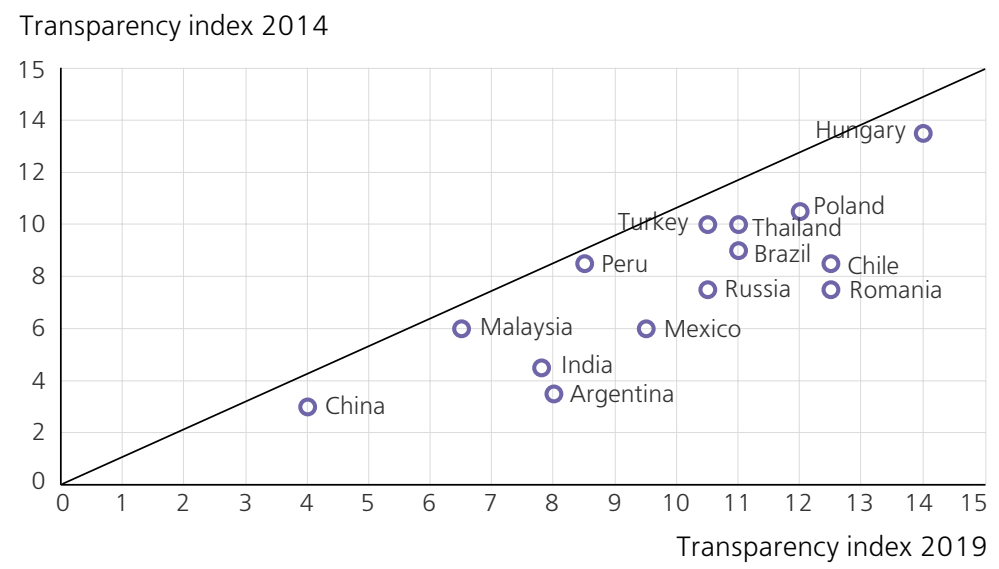

Higher transparency was predominantly the result of more active communication of macroeconomic forecasts by central banks and of more prompt publication of the minutes of meetings. To achieve an even higher transparency level central banks will need to provide more information on their approaches to forecasting, their existing monetary policy rules and voting results at key rate meetings. They will also need to give more detailed accounts of the extent of monetary policy's contribution to price dynamics. The CBR could improve its transparency by focusing on these same areas.

It appears that the less anchored countries have made the most progress and are catching up with the more anchored group in terms of transparency (Figure 5). At the same time, this group has seen a bigger decrease in inflation expectations. Achievements in transparency may at least partly explain increases in inflation expectations anchoring. 
Figure 5. Transparency index and inflation expectations in countries with more and less anchored inflation expectations

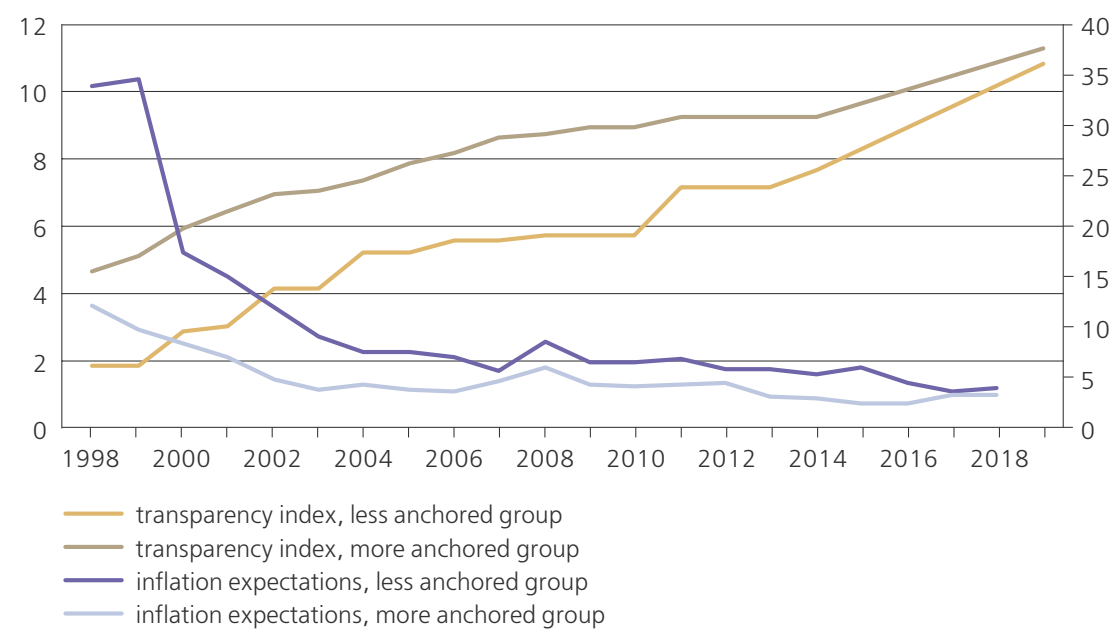

Source: Nordea and Macrobond

The CBR admits that, more than four years after inflation targeting was adopted, inflation expectations remain unanchored. Although they have considerably decreased in recent years, additional efforts are needed for further progress. These measures may be divided into three subcategories.

Firstly, it is important to continue keeping inflation close to the $4 \%$ target to increase the confidence of the population in CBR policy and to confirm the longterm validity of this target and the ability of the CBR to achieve it. The experience of other emerging market countries where inflation used to be significantly above the target (Colombia, the Czech Republic, Romania and Serbia) shows that it may take up to 8-10 years of keeping inflation near or below the target to anchor inflation expectations to the official inflation target.

Secondly, there is significant room for increasing the CBR's transparency and improving the quality of its communication. IMF (2018) and Isakov et al. (2018) note that CBR decisions are often a surprise to the market and are more difficult to forecast than decisions by other EM central banks. These results may signal insufficient understanding of CBR policy on the part of the market.

The following measures may help improve the situation:

- Publication of the minutes of CBR key rate meetings, including a more detailed explanation of the decisions.

- Accompanying all key rate decisions with a press conference by the head of CBR, in line with ECB and FED practice (since 2019). The research outlined in the literature review shows that rate decisions accompanied by press conferences receive wider coverage in the media, raising popular awareness of the regulator's activity. The low predictability of the CBR's actions is partly 
the effect of relatively volatile external conditions. Given this uncertainty, additional press conferences may be warranted.

- More regular speeches by central bank representatives, including explanations of current and future monetary policy stances, providing a basis for the discussion of monetary policy in the media.

- More visible coverage of monetary policy issues on federal TV channels to strengthen the CBR's communication with a broader audience. Even short comments on CBR key rate decisions are often lacking in news releases on the federal TV channels which are an important source of information for a significant proportion of the population. In general, the very limited screen time dedicated to news and programmes with economic content works against efforts to improve the financial literacy of the population.

- Publication of the future interest rate curve. Arguments for and against this initiative are put forward in in detail in Yudaeva (2018) and Isakov et al. (2018). Thirdly, the government and the central bank should continue their efforts to increase the financial literacy of the population. According to OECD research (OECD, 2016), the index of financial literacy in Russia was 12.2 points out of 21 (versus an OECD average of 13.7). Financial literacy is important as even a perfect communication strategy may be inefficient if the target audience is unable to perceive the message because of low financial literacy.

\section{Conclusion}

The key goal of this paper was to ascertain whether anchored inflation expectations helped reduce the macroeconomic consequences of external shocks. To this end we have analysed the period from 2011 to 2019, along with the not yet extensively studied episode of capital outflow from emerging markets in the summer of 2018 in reaction to monetary policy normalization in developed countries. Our estimates have confirmed that countries with less anchored inflation expectations usually face higher exchange rate pass-through to prices. This result was obtained in the estimates for 2011-2019, but not confirmed for a shorter period of FX volatility in emerging markets in 2018. Our results do not tally with the conclusion of the IMF paper (IMF, 2018) which confirmed that FX depreciation had greater inflationary consequences in countries with less anchored inflation expectations after the 'taper tantrum' in 2013. A possible explanation for the difference in results may be the more prudent approach to managing external shocks taken by central banks in 2018. The inflationary consequences of FX depreciation in 2013 encouraged many central banks to switch to a tighter regime faster in 2018 than in 2013.

Although analysis of the 2018 shock has not confirmed that anchored inflation expectations were significantly beneficial, the results for a longer period still point to the importance of inflation anchoring. One way of anchoring inflation expectations is to make central bank policy more transparent. Our update of the central bank 
transparency index first proposed by Dincer and Eichengreen (2007) confirms that in the course of the last five years the transparency of the CBR's monetary policy has been increasing slightly faster than in emerging market countries on average. However, we note that continued progress in communication is needed, with potentially useful measures including the publication of minutes of meetings and more frequent media appearances by CBR representatives. Keeping inflation close to the declared target, further improvement of communication with the market and additional efforts to increase financial literacy are all important elements in the battle with elevated inflation expectations.

\section{Appendices are available at http://rjmf.econs.online/en; dx.doi.org/10.31477/rjmf.201903.71}

\section{References}

Arellano, M. and Bond, S. (1991). Some Tests of Specification for Panel Data: Monte Carlo Evidence and an Application to Employment Equations. Review of Economic Studies, 58(2), pp. 277-297.

Berger, H., Ehrmann, M. and Fratzscher, M. (2006). Monetary Policy in the Media. ECB Working Paper Series, N 679.

Brazier, A., Harrison, R., King, M. and Yates, T. (2008). The Danger of Inflating Expectations of Macroeconomic Stability: Heuristic Switching in an OverlappingGenerations Monetary Model. International Journal of Central Banking, 4(2), pp. 219-254.

Carroll, C. D. (2003). Macroeconomic Expectations of Households and Professional Forecasters. The Quarterly Journal of Economics, 118(1), pp. 269-298.

Dincer, N. and Eichengreen, B. (2007). Central Bank Transparency: Where, Why, and with What Effects? NBER Working Paper, N 13003.

Dincer, N. and Eichengreen, B. (2010). Central Bank Transparency: Causes, Consequences and Updates. Theoretical Inquiries in Law, 11(1), pp. 75-123.

Dincer, N. and Eichengreen, B. (2014). Central Bank Transparency and Independence: Updates and New Measures. International Journal of Central Banking, 10(1), pp. 189-253.

Doepke, M. and Schneider, M. (2006). Aggregate Implications of Wealth Redistribution: The Case of Inflation. Journal of the European Economic Association, 4(2-3), pp. 493-502.

Ehrmann, M. and Fratzscher, M. (2005). Communication and Decision-Making by Central Bank Committees. Different Strategies, Same Effectiveness? ECB Working Paper Series, N 488.

Eijffinger, S. and Geraats, P. (2006). How Transparent are Central Banks? European Journal of Political Economy, 22(1), pp.1-22. 
Freedman, C. and Laxton, D. (2009). Inflation Targeting Pillars: Transparency and Accountability. IMF Working Papers, N 262.

Friedman, M. (1951). Lectures in Price Theory. Unpublished mimeographed notes.

Galati, G., Heemeijer, P. and Moessner, R. (2011). How Do Inflation Expectations Form? New Insights from a High-Frequency Survey. BIS Working Papers, N 349.

Gerberding, C. (2001). The Information Content of Survey Data on Expected Price Developments for Monetary Policy. Economic Research Centre of the Deutsche Bundesbank Discussion Paper, N 9.

International Monetary Fund (2018). World Economic Outlook: Challenges to Steady Growth. Washington, DC: IMF, October, pp. 101-125.

International Monetary Fund (2019). Annual Report on Exchange Arrangements and Exchange Restrictions 2018. Washington, DC: IMF.

Isakov, A., Grishin, P. and Gorlinsky, O. (2018). Fear of Forward Guidance. Russian Journal of Money and Finance, 77(4), pp. 84-106.

Kartaev, F. and Yakimova, Y. (2018). The Influence of Inflation Targeting on the Pass-Through Effect of the Exchange Rate. Voprosy Ekonomiki, 11, pp. 70-84. [In Russian]. doi: 10.32609/0042-8736-2018-11-70-84

Kuznetsova, O. and Merzlyakov, S. (2016). Forward Guidance as an Instrument of the Bank of Russia's Communication Policy. Dengi i Kredit, 11. pp. 19-25. [In Russian]. Available at: https://rjmf.econs.online/archive/2016/11/ [accessed on 24 July 2019].

Loleyt, A. and Gurov, I. (2011). The Process of Formation of Inflation Expectations in an Information Economy. IFC Bulletin, 34, pp. 104-127.

Lucas, R. E. and Sargent, T. J., eds. (1981). Rational Expectations and Econometric Practice. Minneapolis: University of Minnesota Press.

Lyziak, T. (2010). Measuring Consumer Inflation Expectations in Europe and Examining Their Forward-Lookingness. IFC Bulletin, 33, pp. 155-201.

Merzlyakov, S. and Khabibullin, R. (2017). Information Policy of the Bank of Russia: The Influence of the Press Releases on the Interbank Rate. Voprosy Ekonomiki, 11. pp. 141-151. [In Russian]. doi: 10.32609/0042-8736-2017-11-141-151

Mishkin, F. (2000). Inflation Targeting in Emerging-Market Countries. American Economic Review, 90(2), pp. 105-109. doi: 10.1257/aer.90.2.105

Montes, G. C. and Acar, T. (2018). Fiscal Credibility and Disagreement in Expectations about Inflation: Evidence for Brazil. Economics Bulletin, 38(2), pp. 826-843.

OECD (2016). OECD/INFE International Survey of Adult Financial Literacy Competencies. Paris: OECD. Available at: www.oecd.org/finance/OECD-INFE-InternationalSurvey-of-Adult-Financial-Literacy-Competencies.pdf [accessed on 24 July 2019].

Plekhanov, D. (2016). Quantitative Analysis of Press Releases on Monetary Policy. Dengi i Kredit, 5, pp. 45-52. [In Russian]. Available at: https://rjmf.econs.online/ archive/2016/5/ [accessed on 24 July 2019].

Yudaeva, K. (2018). Frontiers of Monetary Policy: Global Trends and Russian Inflation Targeting Practices. Russian Journal of Money and Finance, 77(2), pp. 95-100. 